\title{
The perception of doability and how is it measured
}

\author{
Ryszard Praszkier ${ }^{1}$ iD $\cdot$ Agata Zabłocka $^{2}$
}

Received: 9 September 2020 / Accepted: 15 November 2021 / Published online: 24 November 2021

(c) The Author(s) 2021

\begin{abstract}
This article argues that the propensity to perceive impossible challenges as doable is a personality trait, and presents a method for measuring it. The name coined for this concept is "possibilitivity," a portmanteau of "possible" and "creativity." Possibilitivity is related to such personality traits as self-efficacy and locus of control. This article shows that this trait is embedded in individual cognitive processes, whilst targeting social issues; in this vein, it may be seen as an important mechanism facilitating change-making and transgressing the seemingly impossible. Methodology for assessing this trait is presented, i.e., the process of constructing and validating a questionnaire, its psychometric properties, and some comparisons within the sample $(N=1117)$. One of the findings is that women are significantly more prone to perceive difficult challenges as doable than men. Seeing this study as the first step, further research recommendations are presented, e.g., comparing possibilitivity between various segments of society, as well as analyzing potential correlations with other traits, e.g., empathy or ambiguity tolerance.
\end{abstract}

Keywords Possibilitivity · Challenges · Doability · Transgression · Impossible · Questionnaire

\section{Introduction}

Humans have always strived to achieve the impossible, though they have not always succeeded in their efforts. The Icarus story is iconic for depicting failure in the face of insatiable ambition. This Hellenistic heritage is also found in a business-related phenomenon called the "Icarus Paradox," i.e., scaling too rapidly and failing from over-growth (Amason and Mooney 2008; Miller 1992). Moreover, beginners who do not realize the scope and complexity of their undertakings may overestimate their

Ryszard Praszkier

ryszardpr@gmail.com

1 Institute for Social Studies, University of Warsaw, Kopernika 11 m. 25, 00-359 Warsaw, Poland

2 SWPS University, Warsaw, Poland 
aptitudes-a syndrome called the Dunning-Kruger effect (Kruger and Dunning 1999).

On the contrary, this Hellenistic heritage provides legends of achieving the impossible. For example, Hercules successfully performed the insurmountable and seemingly unrealizable Twelve Labors. To date, we have been on the Moon, and soon, we will be on Mars. Erich Fromm (1990) encouraged us to explore the impossible and overstep limits through philosophy; he believed that, in seeking a higher meaning, individuals try to overstep the boundaries of chaos. Another philosopher, Garry Gutting, documented that French philosophy has been focused on achieving the impossible since the 1960s (Gutting 2013). In addition, the psychologist Abraham Maslow (2019) posited that achieving "self-actualization," the pinnacle of his hierarchy of needs, may require overstepping one's ("apparent") psychological limits.

Exploring the impossible is pivotal in many fields, e.g., in perceiving the philosophy of history as shaped by a passion for "the impossible" (Derrida 1991, 1995; Mason 2007), in inventing a new path for the anthropological understanding of "impossible" cultures (Hauser 2009), and in cognition sciences (Collins 2000). Exceeding oneself has also been a focus of transgression studies (i.e., exploring the impossible and overstepping one's own personal limits) (Barnhart 1988; Madsen 2014; Sokal 1996).

Moreover, there are multiple case studies of social and business innovators who aim to achieve the "unthinkable" and accomplish goals that are perceived by others as undoable (Bornstein 2004; Elkington and Hartigan 2008; Praszkier and Nowak 2012; Praszkier 2018). These individuals go against the influence of the majority (Asch 1956; Deutsch and Gerard 1955; McLeod 2008, 2018) and create their own bubbles of minority influence (De Dreu and De Vries 2001; Vallacher and Nowak 2007; Gardikiotis 2011).

These case studies, delineating how some individuals relate to seemingly impossible challenges, indicate that there exists a specific property for perceiving challenges as doable.

\section{The possibilitivity concept}

This property controls the level of conviction that challenges, even if insurmountable, are achievable. We maintain that each individual has a tendency to evaluate challenges somewhere on the spectrum between two extremes: "It is obviously undoable" and "it is obviously doable." The proposed name for this mind's property is possibilitivity (Praszkier 2019a, b), the name's etymology blending "possible" with "creativity" and echoing the pronunciation of "realizability."

Approximating doability is a cognitive process, stemming from the balance between perceiving one's capabilities and analyzing the features of the challenge. One's capabilities, e.g., self-efficacy, lead to successful outcomes (Akhtar 2008; Bandura 1977, 1982); however, overestimating personal abilities may repress these results (Kruger and Dunning 1999; Stone 2002). Locus of control (i.e., the degree to which people believe that they have control over the outcome of the events in 
their lives), when located internally, leads to perceiving the environment as responsive to one's deliberate actions (Rotter 1966). The other mechanisms that augment one's own capacities may be a belief in the world's and people's changeability (Chiu et al. 1997; Dweck 2000, 2006; Levy et al. 1998), optimism (Carver et al. 2010; Carver and Scheier 2014), and the need for achievement (Brockhaus 2017; McClelland 1961). It may be worth further studies if and how much possibilitivity and these mechanisms overlap. However, possibilitivity is based only partially on estimating own capabilities; it is mainly based on cognitive analyzing a challenge, which may be more or less diligent and informed: In some cases supported by academic knowledge of problem-solving (e.g., Taylor et al. 1994) and mapping the challenge (Harry et al. 2005); in other cases by practical skills ${ }^{1}$ or intuition.

Along these lines, the level of possibilitivity is based on an internal level of one's aptitudes matched with the understanding of the problem; each individual has a specific propensity, locating his or her tendency for perceiving the realizability of challenges on the "obviously not doable-obviously doable" scale.

The development of the possibilitivity concept is a significant advancement in the understanding of the relationship between cognition and social behavior, particular in terms of addressing challenges.

\section{Perception of Doability Questionnaire}

The goal of constructing an assessment tool for measuring possibilitivity is to capture the way people evaluate challenges.

In this spirit, the chosen method was a combination of projective tests (Piotrowski et al. 1993) and the Psychology of Life Stories approach (McAdams 2001), i.e., asking respondents to evaluate the doability of various challenging situations faced by diverse persons. The assumption was that respondents will identify with the presented persons and, while assessing their challenges, will project their own approaches.

Along these lines, twelve stories of diverse individuals aiming at diverse and demanding goals ${ }^{2}$ were initially sketched. Next, seven competent raters evaluated these stories for their clarity and level of difficulty. Finally, the three stories that received the highest clarity rating and a high (though not very high) difficulty rating (extremely difficult situations would not differentiate the responds, as an extremely demanding goal would be seen as obviously undoable by everybody equally). The selected stories were about one man (Collins from Kenya) and two women (Lucky from Nepal and Olga from Columbia). The narrative was located in the moment when these protagonists were planning a novel and challenging solution to some insurmountable and, thus far, intractable problems.

\footnotetext{
1 E.g., through articles for lay readers such as "Analyzing problems," retrieved May 5, 2021 from: https://www.futurelearn.com/info/courses/career-credentials-problem-solving/0/steps/86344.

2 Basing on real-life cases, mostly social and business innovators, partners, and Fellows of the international organization Ashoka, Everyone a Changemaker (www.ashoka.org).
} 
Table 1 Discrimination power of the first pilot $\left(N_{1}=220\right)$ with statements 5 and 6 removed

Table 2 Reliability of the first pilot $\left(N_{1}=220\right)$

\begin{tabular}{llll}
\hline Statements & \multicolumn{2}{l}{ Total correlation } \\
\cline { 2 - 4 } & Collins & Lucky & Olga \\
\hline Statement_r1 & 0.522 & 0.593 & 0.559 \\
Statement_r2 & 0.604 & 0.580 & 0.618 \\
Statement_r3 & 0.511 & 0.569 & 0.439 \\
Statement_r4 & 0.450 & 0.563 & 0.529 \\
Statement_r7 & 0.564 & 0.610 & 0.634 \\
Statement_r8 & 0.485 & 0.563 & 0.644 \\
\hline
\end{tabular}

\begin{tabular}{ll}
\hline Stories & Cronbach's alpha \\
\hline Collins & 0.504 \\
Lucky & 0.575 \\
Olga & 0.481 \\
Total & 0.759 \\
\hline
\end{tabular}

Eight statements served for evaluating the perception of doability (through a Likert scale), e.g., "X seems being on a roll and she/he can do it," "I doubt $X$ will succeed," and "It's too challenging, $X$ will fail."

As the possibilitivity concept is new, it was decided to apply a two-phase validation process: Addressing an $N_{l}>200$ sample and, after initial adjustments, carrying on with a representative sample of the society, $N_{2}>1000$.

\subsection{Validation}

The questionnaire was piloted in two rounds in the Polish population: First pilot, $N_{1}=220$, with 118 women (53.6\%) and 102 men (46.4\%).

Out of the eight statements, six received positive discrimination power, while the other two insufficient discrimination power; after removing the latter two, the discrimination power of the six remaining statements related to the three stories was deemed good (see Table 1).

Moreover, the reliability reached a good level (see Table 2).

The factor analysis revealed that these six statements-in all three cases-fell into two components, which were labeled as "action" (e.g., "In my opinion, Collins will achieve his goals") and "vision" (e.g., "What Collins is planning to do does not look realistic").

In the next step, six new statements were added to the previous six, so as to achieve a balance between both components and between straight and reversed statements. Finally, a 12-statement questionnaire was sent on to the next validation round: Second pilot (or validation round), a representative sample of the Polish society of $N_{2}=1117$. 
Table 3 Age distribution

\begin{tabular}{lrr}
\hline Age & $\#$ & $\%$ \\
\hline $18-24$ & 134 & 12.0 \\
$25-34$ & 226 & 20.2 \\
$35-44$ & 187 & 16.7 \\
$45-54$ & 207 & 18.5 \\
Over 55 & 363 & 32.5 \\
Total & 1117 & 100.0 \\
\hline
\end{tabular}

Table 4 Education level

\begin{tabular}{lrr}
\hline Education level & $\#$ & $\%$ \\
\hline Primary or some high school & 119 & 10.7 \\
High school or equivalent & 507 & 45.4 \\
Bachelor's degree & 119 & 10.7 \\
Master's degree & 285 & 25.5 \\
PhD or higher & 87 & 7.8 \\
Total & 1117 & 100.0 \\
\hline
\end{tabular}

\subsection{The sample}

The sample was representative for the Polish society $\left(N_{2}=1117\right)$ :

575 women $(51.5 \%)$ and 542 men $(48.5 \%)$.

278 subjects $(24.9 \%)$ performed a leadership role, whereas $839(75.1 \%)$ did not. 251 subjects $(22.5 \%)$ were involved in a social project, whereas $866(77.5 \%)$ were not.

For age and education, see Tables 3 and 4.

\subsection{Psychometric parameters of the questionnaire}

Eight (out of twelve) statements were identified as having good discrimination power in relation to all three stories (Table 5).

Moreover, the reliability reached a good level (see Table 6).

Factor analysis (varimax rotation and principal components analysis) did not confirm that the eight statements fall into two components (in any of the three stories). As the second $\left(N_{2}=1117\right)$ sample was representative, this would indicate a final one-factor model.

The final version of the Perception of Doability Questionnaire consists of three stories followed by eight Likert scale statements (see "Appendix"). 
Table 5 Discrimination power of the second pilot $\left(N_{2}=1117\right)$

\begin{tabular}{|c|c|c|c|}
\hline \multirow[t]{2}{*}{ Statements } & \multicolumn{3}{|c|}{ Total correlation } \\
\hline & Collins & Lucky & Olga \\
\hline 1 This challenge is too big, Collins will not make it ${ }^{\mathrm{a}}$ & 0.450 & 0.698 & 0.731 \\
\hline 2 This can be done & 0.726 & 0.817 & 0.848 \\
\hline 3 What Collins is planning to do does not look realistic ${ }^{a}$ & 0.624 & 0.634 & 0.674 \\
\hline 4 Collins' intention is difficult but feasible & 0.509 & 0.652 & 0.765 \\
\hline 5 It looks like Collins is on a roll and he can do it & 0.735 & 0.802 & 0.859 \\
\hline 6 I believe Collins will achieve his goal & 0.769 & 0.817 & 0.860 \\
\hline 7 Collins' vision is convincing & 0.752 & 0.779 & 0.812 \\
\hline 8 I have doubts about whether Collins will succeed ${ }^{\text {a }}$ & 0.640 & 0.700 & 0.730 \\
\hline
\end{tabular}

${ }^{\mathrm{a}}$ Reversed

Table 6 Reliability of the second pilot $\left(N_{2}=1117\right)$

Table 7 Basic psychometric parameters of the Perception of Doability Questionnaire

\begin{tabular}{ll}
\hline Stories & Cronbach's alpha \\
\hline Collins & 0.879 \\
Lucky & 0.920 \\
Olga & 0.939 \\
Total & 0.917 \\
\hline
\end{tabular}

\begin{tabular}{llllll}
\hline & $\mathrm{M}$ & $\mathrm{SD}$ & Skewness & Kurtosis & Reliability \\
\hline $\mathrm{P}_{\mathrm{I}}$ & 3.41 & 0.58 & 0.233 & 0.311 & 0.917 \\
\hline
\end{tabular}

\subsection{Creating a societal index}

The sample $\left(N_{2}=1117\right)$ was prepared as representative of Polish society. In this vein, the assembled data were eligible for constructing a societal index.

The average for possibilitivity, measured as the average result of the eight statements relating to the three stories in the 1117 responses, was $\mathrm{P}_{\mathrm{I}}=3.41$ $(\mathrm{SD}=0.58)$.

The convergence to normal distribution was analyzed using the Kolmogorov-Smirnov test. The results indicate that both skewness and kurtosis are close to zero, which allowed to use the $\mathrm{P}_{\mathrm{I}}$ index as the norm for Polish society (see Table 7).

\subsection{Cross-segment comparative analysis}

To determine if women and men differ in their level of $\mathrm{P}_{\mathrm{I}}$, an independent samples Student's $t$-test was performed. The analysis showed a significant difference: 
Table 8 Difference between the $\mathrm{P}_{\mathrm{I}}$ of men and women

\begin{tabular}{llllll}
\hline Gender & $\#$ & $\mathrm{M}$ & $\mathrm{SD}$ & $t$ & $p$ \\
\hline $\mathrm{P}_{\mathrm{I}}$ & & & & & \\
Women & 575 & 3.5040 & 0.57010 & 5.978 & $<0.001$ \\
Men & 542 & 3.3010 & 0.56415 & & \\
\hline
\end{tabular}

$t(1117)=5.978 ; p<0.001$, with women achieving higher scores than men (see Table 8).

There was no significant difference in the $\mathrm{P}_{\mathrm{I}}$ between age groups, role (i.e., leadership or not), and involvement in social projects.

To determine if gender and age differentiate the $\mathrm{P}_{\mathrm{I}}$ level, a two-way analysis of variance was performed for both five (Table 3) and three age clusters (i.e., 18-34, 35-54, and over 55). The results confirm the differentiating role of gender across the entire population, as well as in each age cluster.

However, neither of these analyses showed any significant difference in $\mathrm{P}_{\mathrm{I}}$ between the age segments.

\section{Results}

The validation process documented that the final eight-statement Perception of Doability Questionnaire is appropriate for both scientific purposes, e.g., comparison between segments of society, and for diagnostic goals, e.g., determining the individual level of possibilitivity. For the latter, the identified possibilitivity index $\left(\mathrm{P}_{\mathrm{I}}\right)$ reflects the societal average.

\section{Conclusions}

The propensity for perceiving insurmountable challenges as doable seems an important property, especially in the context of human social activity. It is embedded, on the one hand, in individual cognitive processes and, on the other hand, relates to social, business, or political issues, and as such, it forms a foundational mechanism for change-making and transgressing the seemingly impossible.

This is the first step in identifying and understanding the concept of possibilitivity, which is worth further study. It is especially important to research how possibilitivity relates to other characteristics, e.g., the Empathy Quotient Short (Wakabayashi et al. 2006), the Adversity Quotient (Stoltz, 1999), ambiguity tolerance (Bochner, 1965; Budner 1962), or creativity and divergent thinking (e.g., Runco and Acar 2012). It is also important to perform further comparative studies, comparing diverse segments of society.

For these purposes, the Perception of Doability Questionnaire seems a good fit. Herein, it was tested in the Polish culture, and it seems important to verify and adapt it to other cultures as well. Moreover, it would be important to cross-culturally 
analyze the outcomes mentioned in this paper. For example, it is intriguing that there was not a significant difference between those engaged in social projects and those not involved-does this occur in other cultures as well?

It would be especially valuable to analyze whether the significantly higher $\mathrm{P}_{\mathrm{I}}$ level in Polish females also manifests in other cultures. If it does, then it may shed some new light on the existing and potential role of women as change-makers. If it is exclusive to Poland, then this may be attributable to the role women have played in Polish protest movements, especially in the Polish underground peaceful solidarity movement of the 1980s (Brown 2003; Penn 2006) and the 2020-2021 well-organized Polish anti-government protests and demonstrations (Women Strike protests). ${ }^{3}$ These leadership roles, successfully performed by women, as well as the higher education level reached by women (compared to men), may have contributed to their stronger possibilitivity conviction.

Finally, as the possibilitivity level matters in solving human problems, it seems valuable to identify methods of training, especially for future leaders and the younger generation, that augment their propensity for perceiving challenges as doable. This may be especially critical in conflict areas for innovating peace-making methods, or in high-poverty areas for creating novel solutions to combat hunger and impoverishment. Further studies may identify methods to increase the level of conviction so that the thus far intractable, though pressing, problems may be successfully addressed.

\section{Appendix: Perception of Doability Questionnaire}

\section{The three stories}

\section{Collins, Kenya}

As a high school student, Collins from Kenya was interested in technical lessons. He noticed that various assignments (e.g., making figurines) are performed sloppily and are thrown away after students receive their grades. He had an idea to not only increase the quality of work performed, but also to make money from it. After graduating, Collins decided to register a venture for contracting, for a small fee, students' products that have already been "passed" and selling them over the Internet. For this purpose, he had to establish very high standards for "producing" items in technical lessons.

He hopes that he not only makes money by buying and then selling handcraft products, but that students will learn more by pursuing higher (market) standards and that teachers will be satisfied with the results of their teaching.

$\mathrm{He}$ is planning an acquisition network covering the whole of Kenya and-separately_a special Allegro-like platform for selling abroad.

\footnotetext{
3 See: https://en.wikipedia.org/wiki/2020\%E2\%80\%932021_women\%27s_strike_protests_in_Poland. Accessed 5 May 2021.
} 
Collins' goals are to build a network of hand-crafted products redistributed throughout Kenya, while increasing the level of technical skills of young people and providing them with a small allowance.

\section{Lucky, Nepal}

High in the Himalayas, villages are cut off from the world, from which the journey for bread or other goods takes several days. Usually, women stay in the villages because men find work in the Kathmandu valley or in British or UN military missions as specialists in mountain operations.

The problem is that education, especially of girls, is completely neglected: One can imagine the difficulties teachers face in reaching the next high-mountain Himalayan village. The issue is made more acute by parents who do not see any sense in educating girls, whom they believe are destined to work in households.

Lucky, who is from one of these villages, always had a drive for education and also wanted to enable girls from similar villages to receive an education. She began to wonder: Maybe you need to approach the matter from a different angle by finding a profession that is related to the mountains, that would be universally accepted, and during training for this profession, "smuggle" in regular education?

Such a profession, according to Lucky, could be guidance through high-altitude mountainous areas. She thought about establishing a female Himalayan guide school. This was about "their" mountains after all, so she counted on parents' support. During the training, she planned to teach the girls English (needed to communicate with clients), geography (orientation in the field), biology (about the species found in the mountains), etc.

She thought that the planned school could be quite popular, more so than traditional men's schools, given the empathy and lower competitiveness of women.

She also thought that, during the off-season, the students of her guide school should be required to pass on new knowledge to other children and women, when back in their villages. Thanks to this, girls would not only bring in an income, but also become valued educators. Additionally, the success of the female guide school would change the image of women in Nepalese society.

Lucky's goal is to educate girls in hard-to-reach Himalayan settlements and, at the same time, change the image of women in Nepal.

\section{Olga, Columbia}

Olga grew up in extreme poverty in Colombian slums. Having cleaned rich homes since she was a child, Olga saw a wealth of food and dreamed of children from poor backgrounds also having enough to eat, with access to dietary supplements (vitamins and minerals).

She was self-taught-learning by reading books from the shelves of the houses where she worked. One day, she read a book on banking, which made a great impression on her. She thought: How about creating a bank that trades waste instead of money? A normal bank, running accounts, counters, payment cards, and loans, with the difference that, instead of money, clients would bring collected waste, for 
which they would be awarded points to their account. Then, with these points, using the bank's payment card, they could buy food and dietary supplements in the bank's shop.

For children and youths, the bank would also provide education in the field of economics, marketing, and banking.

Olga also thought that the bank's customers should be able to take out insurance through the surplus of waste deposited: In the event of an illness, the insurance would cover the necessary rations of food. She also thought about food loans in emergencies, which could be repaid later with waste.

The bank would sell the collected waste to factories for recycling, and the resulting profit would be invested in replicating similar banks in other poor regions of Colombia and Latin America.

Olga's goal is to provide food for children and families from the poorest regions of Colombia and Latin America.

\section{The eight statements}

\begin{tabular}{lll}
\hline 1 & This challenge is too big, Collins will not make it $^{\mathrm{a}}$ & 12345 \\
\hline 2 & This can be done & 12345 \\
3 & What Collins is planning to do does not look realistic & $\mathrm{a}$ \\
4 & Collins' intention is difficult but feasible & 12345 \\
5 & It looks like Collins is on a roll and he can do it & 12345 \\
6 & I believe Collins will achieve his goal & 12345 \\
7 & Collins' vision is convincing & 12345 \\
8 & I have doubts about whether Collins will succeed $^{\mathrm{a}}$ & 12345 \\
\hline
\end{tabular}

${ }^{\mathrm{a}}$ Reversed

Acknowledgments Thank you to Prof. Jacek Koronacki, Ph.D., for his important suggestions regarding the statistical analysis. Thank you to James Ursell, Ph.D., for his editorial skills and significant comments and suggestions; also, thank you to Taylor Leet-Otley and Paige Munnik for their editorial contribution. This article is assigned to the Robert B. Zajonc Institute for Social Studies, University of Warsaw. The questionnaire and research procedure were approved by the Research Ethics Committee, University of Warsaw.

\section{Declarations}

Conflict of interest The authors declare that they have no known competing financial interests or personal relationships that could have appeared to influence the work reported in this paper.

Ethical approval The questionnaire and research procedure is approved by the Research Ethics Committee, University of Warsaw.

Open Access This article is licensed under a Creative Commons Attribution 4.0 International License, which permits use, sharing, adaptation, distribution and reproduction in any medium or format, as long as you give appropriate credit to the original author(s) and the source, provide a link to the Creative 
Commons licence, and indicate if changes were made. The images or other third party material in this article are included in the article's Creative Commons licence, unless indicated otherwise in a credit line to the material. If material is not included in the article's Creative Commons licence and your intended use is not permitted by statutory regulation or exceeds the permitted use, you will need to obtain permission directly from the copyright holder. To view a copy of this licence, visit http://creativecommons.org/ licenses/by/4.0/.

\section{References}

Akhtar, M. (2008). What is self-efficacy? Bandura's 4 sources of efficacy beliefs. Posit Psychol. http:// positivepsychology.org.uk/self-efficacy-definition-bandura-meaning/. Accessed 5 May 2021

Amason AC, Mooney AC (2008) The Icarus paradox revisited: how strong performance sows the seeds of dysfunction in future strategic decision-making. Strateg Organ 6(4):407-434. https://doi.org/10. $1177 / 1476127008096364$

Asch SE (1956) Studies of independence and conformity: I. A minority of one against a unanimous majority. Psychol Monogr Gen Appl 70(9):1-70. https://doi.org/10.1037/h0093718

Bandura A (1977) Self-efficacy: toward a unifying theory of behavioral change. Psychol Rev 84(2):191215. https://doi.org/10.1037/0033-295X.84.2.191

Bandura A (1982) Self-efficacy mechanism in human agency. Am Psychol 37(2):122-147. https://doi. org/10.1037/0003-066X.37.2.122

Barnhart RK (ed) (1988) The Barnhart dictionary of etymology. The H.W. Wilson Company, New York

Bochner S (1965) Defining intolerance of ambiguity. Psychol Rec 15(3):393-400

Bornstein D (2004) How to change the world. Social entrepreneurs and the power of new ideas. Oxford University Press, New York

Brockhaus RH (2017) Risk taking propensity of entrepreneurs. Acad Manag J 23(3):509-520. https://doi. org/10.2307/255515

Brown, B. (2003). The private revolution: women in the Polish Underground Movement. Hera Trust, London

Budner S (1962) Intolerance of ambiguity as a personality variable. J Pers 30(1):29-50. https://doi.org/ 10.1111/j.1467-6494.1962.tb02303.x

Carver CS, Scheier MF, Segerstrom SC (2010) Optimism. Clin Psychol Rev 30(7):879-889. https://doi. org/10.1016/j.cpr.2010.01.006

Carver CS, Scheier MF (2014) Dispositional optimism. Trends Cogn Sci 18(6):293-299. https://doi.org/ 10.1016/j.tics.2014.02.003

Chiu C, Dweck CS, Tong JY, Fu JH (1997) Implicit theories and conceptions of morality. J Pers Soc Psychol 73(5):923-940. https://doi.org/10.1037/0022-3514.73.5.923

Collins G (2000) Thinking the impossible: Derrida and the divine. Liter Theol 14(3):313-334

De Dreu SKW, De Vries NK (2001) Group consensus and minority influence: introduction and overview. In: De Dreu SKW, De Vries NK (eds) Group consensus and minority influence: implications for innovation. Blackwell, Oxford, pp 1-14

Derrida J (1991) Given time. University of Chicago Press, Chicago

Derrida J (1995) The gift of death. University of Chicago Press, Chicago

Deutsch M, Gerard HB (1955) A study of normative and informational social influences upon individual judgment. J Abnorm Soc Psychol 51(3):629-636. https://doi.org/10.1037/h0046408

Dweck CS (2000) Self-theories: their role in motivation, personality, and development. Psychology Press, Philadelphia

Dweck CS (2006) Mindset. The new psychology of success. Random House, New York

Elkington J, Hartigan P (2008) The power of unreasonable people. Harvard Business Press, Boston

Fromm E (1990) The sane society. Holt Paperbacks, New York

Gardikiotis A (2011) Minority influence. Soc Person Psychol Compass 5(9):679-693. https://doi.org/10. 1111/j.1751-9004.2011.00377.x

Gutting G (2013) Thinking the impossible: French Philosophy since 1960. Oxford University Press, New York

Harry B, Sturges KM, Klingner JK (2005) Mapping the process: an exemplar of process and challenge in grounded theory analysis. Educ Res 34(2):3-13. https://doi.org/10.3102/0013189X034002003 
Hauser MD (2009) The possibility of impossible cultures. Nature 460:190-196. https://doi.org/10.1038/ $460190 \mathrm{a}$

Madsen OJ (2014) Transgression. In: Teo T (ed) Encyclopedia of critical psychology. Springer, New York

Maslow AH (2019) Motivation and personality. Prabhat Prakashan, New Delhi

Mason M (2007) Exploring 'the impossible': Jacques Derrida, John Caputo and the philosophy of history. Rethink Hist 10(4):501-522. https://doi.org/10.1080/13642520600816106

Kruger J, Dunning D (1999) Unskilled and unaware of it: how difficulties in recognizing one's own incompetence lead to inflated self-assessments. J Pers Soc Psychol 77(6):1121-1134. https://doi.org/ 10.1037/0022-3514.77.6.1121

Levy SR, Stroessner SJ, Dweck CS (1998) Stereotype formation and endorsement: the role of implicit theories. J Pers Soc Psychol 74(6):1421-1436. https://doi.org/10.1037/0022-3514.74.6.1421

McAdams DP (2001) The psychology of life stories. Rev Gen Psychol 5(2):100-122. https://doi.org/10. 1037/1089-2680.5.2.100

McClelland DC (1961) The achieving society. Free Press, New York

McLeod, S. (2008). Asch experiment. Simply Psychology. http://www.simplypsychology.org/asch-confo rmity.html. Accessed 5 May 2021

McLeod, S. (2018). Moscovici and minority influence. Simply Psychology. http://www.simplypsychology.org/minority-influence.html. Accessed 5 May 2021

Miller D (1992) The Icarus paradox: how exceptional companies bring about their own downfall. Bus Horiz 35(1):24-35. https://doi.org/10.1016/0007-6813(92)90112-M

Penn S (2006) Solidarity's secret: the women who defeated communism in Poland. University of Michigan Press, Ann Arbor

Piotrowski C, Keller JW, Ogawa T (1993) Projective techniques: an international perspective. Psychol Rep 72(1):179-182. https://doi.org/10.2466/pr0.1993.72.1.179

Praszkier R (2018) Empowering leadership of tomorrow. Cambridge University Press, New York, NY

Praszkier R (2019a) Working wonders: how to make the impossible happen. Cambridge University Press, New York, NY

Praszkier R (2019b) The anatomy of Obama's "Yes We Can”. iASK Polányi Centre Publications, working paper II.2019/WP01

Praszkier R, Nowak A (2012) Social entrepreneurship: theory and practice. Cambridge University Press, New York, NY

Rotter JB (1966) Generalized expectancies for internal versus external control of reinforcement. Psychol Monogr Gen Appl 80(1):1-28. https://doi.org/10.1037/h0092976

Runco MA, Acar S (2012) Divergent thinking as an indicator of creative potential. Creat Res J 24(1):6675. https://doi.org/10.1080/10400419.2012.652929

Sokal A (1996) Transgressing the boundaries: towards a transformative hermeneutics of quantum gravity. Soc Text 46-47:217-252

Stoltz PG (1999) Adversity quotient: turning obstacles into opportunities. Wiley, New York

Stone DN (2002) Overconfidence in initial self-efficacy judgments: effects on decision processes and performance. Organ Behav Hum Decis Process 59(3):452-474. https://doi.org/10.1006/obhd.1994. 1069

Taylor JC, Lashman R, Helling P (1994) Practical problem-solving skills in the workplace. American Management Association, New York

Vallacher RR, Nowak A (2007) Dynamical social psychology: finding order in the flow of human experience. In: Kruglanski AW, Higgins ET (eds) Social psychology: handbook of basic principles. Guilford Publications, New York, pp 734-758

Wakabayashi A, Baron-Cohen S, Wheelwright S, Goldenfeld N, Delaney J, Fine D, Smith R, Weil L (2006) Development of short forms of the Empathy Quotient (EQ) and the Systemizing Quotient (SQ). Personal Individ Differ 41(5):929-940. https://doi.org/10.1016/j.paid.2006.03.017

Publisher's Note Springer Nature remains neutral with regard to jurisdictional claims in published maps and institutional affiliations. 